\title{
The effect of proton pump inhibitors on the gastric mucosal microenvironment
}

\author{
Yen-Chun Peng 9, 2, 3, A-F, Lan-Ru Huang ${ }^{4, A, C, E}$, Hui-Ching Ho 5, C, Chi-Sen Chang 4, C, E, Shou-Wu Lee ${ }^{1, E}$, \\ Ching-Chang Cheng, E, May-Ching Wen ${ }^{8,},{ }^{7}$, Hong-Zen Yeh", E, Shu-Peng Ho ${ }^{2, A, E, F}$ \\ 1 Division of Gastroenterology, Department of Internal Medicine,Taichung Veterans General Hospital, Taichung, Taiwan \\ 2 Department of Veterinary Medicine, School of Medicine, National Chung Hsing University, Taichung, Taiwan \\ ${ }^{3}$ National Yang Ming University, Taipei, Taiwan \\ ${ }^{4}$ Department of Medical Laboratory Science and Biotechnology, Central Taiwan University of Science and Technology, Taichung, Taiwan \\ ${ }^{5}$ Department of Medical Research, Taichung Veterans General Hospital, Taichung, Taiwan \\ ${ }^{6}$ Department of Internal Medicine, Taichung Veterans General Hospital, Taichung, Taiwan \\ ${ }^{7}$ Laboratory Animal Service Center, Office of Research and Development, China Medical University, Taichung, Taiwan \\ ${ }^{8}$ Department of Pathology, Taichung Veterans General Hospital, Taichung, Taiwan \\ A - research concept and design; $\mathrm{B}$ - collection and/or assembly of data; $\mathrm{C}$ - data analysis and interpretation; \\ $D$ - writing the article; $E$ - critical revision of the article; $F$ - final approval of article
}

Address for correspondence

Shu-Peng Ho

E-mail: spho@dragon.nchu.edu.tw

\section{Funding sources}

none declared

Conflict of interest

none declared

\section{Acknowledgments}

This study was supported by a grant from Taichung Veterans General Hospital (TCVGH-977203B). We thank the Biostatistics Task Force of Taichung Veterans General Hospital for statistical assistance.

Received on January 24, 2014 Revised on 0ctober 13, 2014 Accepted on 0ctober 30, 2014

DOI

10.17219/acem/33116

\section{Copyright}

Copyright by Author(s)

This is an article distributed under the terms of the

Creative Commons Attribution Non-Commercial License

(http://creativecommons.org/licenses/by-nc-nd/4.0/)

\section{Abstract}

Background. Proton pump inhibitors (PPIs) are widely applied for acid related disorders, and possess pleiotropic biological functions. The effect of PPIs on the gastric mucosa, neutrophil and Helicobacter pylori (H. pylori) infiltration and glandular atrophy has not been well investigated, particularly the duration of the effects of PPIs.

Objectives. To investigate the effects of PPIs on neutrophil infiltration, H. pylori infiltration and the gastric mucosa.

Material and methods. A total of 76 adult patients with gastrointestinal symptoms who had undergone upper gastrointestinal endoscopy were enrolled in the study. Each patient's history was recorded, including smoking, alcohol consumption and the duration of PPI use prior to gastric biopsy. Endoscopic biopsies of gastric antral mucosa were performed and evaluated by histology. Neutrophil and $H$. pylori infiltration were graded by $H$ \& E staining in accordance with the updated Sydney system.

Results. Among the 76 patients, 44 patients had H. pylori infection and 19 patients had taken PPIs for varying durations prior to gastric biopsy. Neutrophil infiltration was significantly inhibited by PPIs ( $p=0.005)$. The duration of PPI use was correlated with inhibition of neutrophil and H. pylori infiltration. A logistical regression analysis demonstrated that PPIs significantly inhibited neutrophil infiltration in the gastric mucosa and were associated with atrophy of the mucosa.

Conclusions. PPIs attenuated neutrophil infiltration of gastric mucosa, and may be related to atrophy of the mucosa.

Key words: Helicobacter pylori, gastric mucosa, proton pump inhibitor, neutrophil 
Proton pump $(\mathrm{H}+/ \mathrm{K}+$-adenosine triphosphatase [ATPase]) inhibitors (PPIs) have been widely used for the treatment of acid-related disorders since the mid-1980s due to their strong anti-secretory effect, and have become one of the most important treatment strategies for acidrelated gastrointestinal disorders. ${ }^{1}$ Both short- and longterm adverse effects of PPI use, including increased risk of infection, neoplasia and drug interaction, have been reported. PPIs may also affect gastric mucosal inflammation, attenuate neutrophil functions and cause hypochlorhydria. ${ }^{2-4}$

Neutrophils have long been viewed as short-lived effector cells of the innate immune system; they are recruited to the site of inflammation and generate reactive oxygen and nitrogen species. ${ }^{5}$ With their destructive potential, neutrophils enter peripheral tissue and interact closely with host cells. ${ }^{5,6}$ Helicobacter pylori (H. pylori) infection is a global threat and commonly persists for life unless treated. H. pylori is one of the major factors related to the pathogenesis of gastric mucosa injury and the main cause of chronic gastritis, gastric mucosal atrophy, peptic ulcer and some forms of gastric cancer. ${ }^{7}$ The recruited neutrophils participate in the complex process of gastric inflammation, including biochemical tissue injury and immunological response. Although the precise mechanism of the development of gastritis is still not very clear, it may be related to the combined influences of bacterial toxin and cytokines on recruited neutrophils. ${ }^{8}$

The first PPI, omeprazole, has been proven to attenuate neutrophil and lymphocyte functions in vitro. ${ }^{9-12}$ PPIs affect the interaction of neutrophils with endothelial cells and attenuate neutrophil association with chemostatic cytokines of gastric mucosa. ${ }^{2,4,13}$ However, the effect of PPIs on gastric mucosa and neutrophils has not been thoroughly clarified. ${ }^{14,15}$ This study investigated the effect of PPIs on $H$. pylori, neutrophil infiltration and gastric antral mucosa inflammation.

\section{Material and Methods}

\section{The patients}

A total of 76 patients with gastritis, with or without peptic ulcer disease, were enrolled in the study. At least 2 biopsy specimens of antral mucosa of the stomach were taken during endoscopy for evaluation of the gastric mucosal inflammation status. Each patient's medical history and basic demographic data were obtained from their medical records and by taking their histories. All the subjects provided informed consent before the endoscopy. The study was approved by the Institutional Review Board of Taichung Veterans General Hospital.

\section{Endoscopy and disease assessment}

An experienced endoscopist performed the gastrointestinal endoscopies. Biopsy specimens were taken from the antrum of the stomach of all 76 patients to evaluate the gastric mucosal inflammatory status. Gastric ulcers, duodenal ulcers and reflux esophagitis were diagnosed endoscopically.

\section{Histological assessments}

Biopsy specimens were examined with hematoxylineosin (HE) staining. The specimens from the antrum were assessed for the presence of $H$. pylori, neutrophil infiltration, lymphocyte infiltration, glandular atrophy and intestinal metaplasia. Intestinal metaplasia was evaluated morphologically by the presence of goblet cells, absorptive cells and cells resembling clonocytes. Neutrophil infiltration was diagnosed by the presence of polymorphonuclear leukocytes in the lamina propria of the gastric mucosa. H. pylori infection, neutrophil infiltration, lymphocyte infiltration, intestinal metaplasia and glandular atrophy were classified as none, mild, moderate and severe according to the updated Sydney system. ${ }^{16}$

\section{Statistical analysis}

All the statistical analyses were carried out using the Statistical Package for Social Sciences (version 15.1; SPSS, Inc., Chicago, USA) and SAS 9.1.3 (SAS Institute Inc., Cary, USA). Continuous variables are expressed as means \pm SD. The Kruskal-Wallis test or Mann-Whitney $\mathrm{U}$ test was used for inter-group comparisons of continuous variables. The $\chi^{2}$ test with Yates' correction was used for the comparisons of discrete variables, gender, the presence/absence of $H$. pylori infection and the histology grading of neutrophil infiltration. Forward stepwise logistic regression analysis was used for comparisons of histological variables among PPI users and non-PPI users. For two-group comparisons a two-sided $\mathrm{p}$ value of less than 0.05 was considered statistically significant.

\section{Results}

\section{PPI use, peptic ulcer type and $H$. pylori affect neutrophil infiltration}

A total of 76 patients (46 females and 30 males, mean age 56.6 years) were examined. Among them 19 patients were taking PPIs and 57 patients were not taking PPIs in the 3 months prior to their endoscopic examinations. The baseline clinical characteristics of the patients and variables affecting neutrophil infiltration are shown in 
Table 1: Patient variables that affect neutrophil infiltration

\begin{tabular}{|c|c|c|c|c|c|c|c|c|c|c|}
\hline \multirow{3}{*}{ Variable } & \multirow{3}{*}{ Grade } & \multicolumn{8}{|c|}{ Neutrophil infiltration } & \multirow{3}{*}{ P-value } \\
\hline & & \multicolumn{2}{|c|}{ none $(n=22)$} & \multicolumn{2}{|c|}{ mild $(n=26)$} & \multicolumn{2}{|c|}{ moderate $(n=16)$} & \multicolumn{2}{|c|}{ marked $(n=12)$} & \\
\hline & & $\mathrm{n}$ & (\%) & $\mathrm{n}$ & (\%) & $\mathrm{n}$ & (\%) & $\mathrm{n}$ & $(\%)$ & \\
\hline Age & & 62.55 & \pm 16.56 & 62.15 & \pm 18.22 & 59.88 & \pm 8.61 & 54.67 & \pm 9.44 & $0.446^{b}$ \\
\hline Gender & $\begin{array}{c}m \\
f\end{array}$ & $\begin{array}{l}10 \\
12\end{array}$ & $\begin{array}{l}(45.5) \\
(54.5)\end{array}$ & $\begin{array}{l}11 \\
15\end{array}$ & $\begin{array}{l}(42.3) \\
(57.7)\end{array}$ & $\begin{array}{r}3 \\
13\end{array}$ & $\begin{array}{l}(18.8) \\
(81.3)\end{array}$ & $\begin{array}{l}6 \\
6\end{array}$ & $\begin{array}{l}(50.0) \\
(50.0)\end{array}$ & $0.278^{a}$ \\
\hline PPI $\underline{s}$ & $\begin{array}{l}\text { without } \\
\text { with }\end{array}$ & $\begin{array}{l}11 \\
11\end{array}$ & $\begin{array}{l}(50.0) \\
(50.0)\end{array}$ & $\begin{array}{r}20 \\
6\end{array}$ & $\begin{array}{l}(76.9) \\
(23.1)\end{array}$ & $\begin{array}{r}14 \\
2\end{array}$ & $\begin{array}{l}(87.5) \\
(12.5)\end{array}$ & $\begin{array}{r}12 \\
0\end{array}$ & $\begin{array}{r}(100.0) \\
(0.0)\end{array}$ & $0.005 * * a$ \\
\hline NSAIDs & $\begin{array}{l}\text { without } \\
\text { with }\end{array}$ & $\begin{array}{r}21 \\
1\end{array}$ & $\begin{array}{r}(95.5) \\
(4.5)\end{array}$ & $\begin{array}{r}26 \\
0\end{array}$ & $\begin{array}{r}(100.0) \\
(0.0)\end{array}$ & $\begin{array}{r}15 \\
1\end{array}$ & $\begin{array}{r}(93.8) \\
(6.3)\end{array}$ & $\begin{array}{r}12 \\
0\end{array}$ & $\begin{array}{r}(100.0) \\
(0.0)\end{array}$ & $0.540^{a}$ \\
\hline Smoking & $\begin{array}{l}\text { without } \\
\text { with }\end{array}$ & $\begin{array}{r}19 \\
3\end{array}$ & $\begin{array}{l}(86.4) \\
(13.6)\end{array}$ & $\begin{array}{r}26 \\
0\end{array}$ & $\begin{array}{r}(100.0) \\
(0.0)\end{array}$ & $\begin{array}{r}14 \\
2\end{array}$ & $\begin{array}{l}(87.5) \\
(12.5)\end{array}$ & $\begin{array}{r}11 \\
1\end{array}$ & $\begin{array}{r}(91.7) \\
(8.3)\end{array}$ & $0.296^{a}$ \\
\hline UGl scopy & $\begin{array}{c}\text { GU } \\
\text { DU } \\
\text { GU + DU } \\
\text { gastritis } \\
\text { esophagitis }\end{array}$ & $\begin{array}{l}6 \\
5 \\
1 \\
1 \\
9\end{array}$ & $\begin{array}{r}(27.3) \\
(22.7) \\
(4.5) \\
(4.5) \\
(40.9)\end{array}$ & $\begin{array}{r}12 \\
5 \\
1 \\
4 \\
4\end{array}$ & $\begin{array}{r}(46.2) \\
(19.2) \\
(3.8) \\
(15.4) \\
(15.4)\end{array}$ & $\begin{array}{l}4 \\
9 \\
3 \\
0 \\
0\end{array}$ & $\begin{array}{r}(25.0) \\
(56.3) \\
(18.8) \\
(0.0) \\
(0.0)\end{array}$ & $\begin{array}{l}3 \\
4 \\
5 \\
0 \\
0\end{array}$ & $\begin{array}{r}(25.0) \\
(33.3) \\
(41.7) \\
(0.0) \\
(0.0)\end{array}$ & $0.0004 * * a$ \\
\hline $\begin{array}{l}\text { H. pylori } \\
\text { (histology) }\end{array}$ & $\begin{array}{l}\text { none } \\
\text { mild } \\
\text { moderate } \\
\text { severe }\end{array}$ & $\begin{array}{r}19 \\
3 \\
0 \\
0\end{array}$ & $\begin{array}{r}(86.4) \\
(13.6) \\
(0.0) \\
(0.0)\end{array}$ & $\begin{array}{r}19 \\
3 \\
3 \\
1\end{array}$ & $\begin{array}{r}(73.1) \\
(11.5) \\
(11.5) \\
(3.8)\end{array}$ & $\begin{array}{l}6 \\
2 \\
4 \\
4\end{array}$ & $\begin{array}{l}(37.5) \\
(12.5) \\
(25.0) \\
(25.0)\end{array}$ & $\begin{array}{l}0 \\
1 \\
6 \\
5\end{array}$ & $\begin{array}{r}(0.0) \\
(8.3) \\
(50.0) \\
(41.7)\end{array}$ & $<0.0001 * * a$ \\
\hline $\begin{array}{l}\text { H. pylori } \\
\text { (histology) }\end{array}$ & $\begin{array}{c}\text { negative } \\
\text { positive }\end{array}$ & $\begin{array}{r}19 \\
3\end{array}$ & $\begin{array}{l}(86.4) \\
(13.6)\end{array}$ & $\begin{array}{r}19 \\
7\end{array}$ & $\begin{array}{l}(73.1) \\
(26.9)\end{array}$ & $\begin{array}{r}6 \\
10\end{array}$ & $\begin{array}{l}(37.5) \\
(62.5)\end{array}$ & $\begin{array}{r}0 \\
12\end{array}$ & $\begin{array}{r}(0.0) \\
(100.0)\end{array}$ & $<0.0001 * * a$ \\
\hline
\end{tabular}

a Pearson $\chi^{2}$ test; ${ }^{b}$ Kruskal-Wallis test; ${ }^{*} p<0.05 ;{ }^{* *} p<0.01$

Table 1. Among the 76 patients, there were no differences in grades of neutrophil infiltration based on age, gender, NSAID use and smoking history. The use of PPIs prior to endoscopic examination significantly affected neutrophil infiltration. The results demonstrated that patients who were taking PPIs tended to have less neutrophil infiltration in the gastric mucosa than non-PPI users.

\section{PPI use modulates neutrophil infiltration, lymphocyte infiltration and atrophy of the mucosa}

The histological characteristics of PPI users and nonPPI users are shown in Table 2. Patients taking PPIs had less neutrophil infiltration and lymphocyte infiltration ( $\mathrm{p}=0.005$ and 0.009 , respectively). Though only $41 \mathrm{pa}-$ tients (54\%), the atrophy index of mucosa was also more

Table 2. Histological variables in patients who used or did not use PPIs

\begin{tabular}{|c|c|c|c|c|c|c|}
\hline \multirow{3}{*}{ Variable } & \multirow{3}{*}{ Grade } & \multicolumn{4}{|c|}{ PPI } & \multirow{3}{*}{ P-value } \\
\hline & & \multicolumn{2}{|c|}{ without PPI $(n=57)$} & \multicolumn{2}{|c|}{ with PPI $(n=19)$} & \\
\hline & & $\mathrm{n}$ & $(\%)$ & $\mathrm{n}$ & $(\%)$ & \\
\hline Neutrophil infiltration & $\begin{array}{c}\text { none } \\
\text { mild } \\
\text { moderate } \\
\text { severe }\end{array}$ & $\begin{array}{l}11 \\
20 \\
14 \\
12\end{array}$ & $\begin{array}{l}(19.3) \\
(35.1) \\
(24.6) \\
(21.1)\end{array}$ & $\begin{array}{r}11 \\
6 \\
2 \\
0\end{array}$ & $\begin{array}{r}(57.9) \\
(31.6) \\
(10.5) \\
(0.0)\end{array}$ & $0.005 * * a$ \\
\hline Chronic inflammation & $\begin{array}{c}\text { none } \\
\text { mild } \\
\text { moderate } \\
\text { severe }\end{array}$ & $\begin{array}{r}0 \\
14 \\
23 \\
20\end{array}$ & $\begin{array}{r}(0.0) \\
(24.6) \\
(40.4) \\
(35.1)\end{array}$ & $\begin{array}{r}0 \\
11 \\
7 \\
1\end{array}$ & $\begin{array}{r}(0.0) \\
(57.9) \\
(36.8) \\
(5.3)\end{array}$ & $0.009 *$ a \\
\hline Atrophy & $\begin{array}{c}\text { none } \\
\text { mild } \\
\text { moderate } \\
\text { severe }\end{array}$ & $\begin{array}{r}25 \\
5 \\
1 \\
0\end{array}$ & $\begin{array}{r}(80.6) \\
(16.1) \\
(3.2) \\
(0.0)\end{array}$ & $\begin{array}{l}4 \\
6 \\
0 \\
0\end{array}$ & $\begin{array}{r}(40.0) \\
(60.0) \\
(0.0) \\
(0.0)\end{array}$ & $0.023 * a$ \\
\hline Intestinal metaplasia & $\begin{array}{c}\text { none } \\
\text { mild } \\
\text { moderate } \\
\text { severe }\end{array}$ & $\begin{array}{r}34 \\
14 \\
7 \\
2\end{array}$ & $\begin{array}{r}(59.6) \\
(24.6) \\
(12.3) \\
(3.5)\end{array}$ & $\begin{array}{r}11 \\
7 \\
1 \\
0\end{array}$ & $\begin{array}{r}(57.9) \\
(36.8) \\
(5.3) \\
(0.0)\end{array}$ & $0.548^{a}$ \\
\hline
\end{tabular}

a Pearson $\chi^{2}$ test; ${ }^{b}$ Yates' correction for continuity; ${ }^{*} p<0.05 ;{ }^{* *} p<0.01$. 
severe in PPI users than non-PPI users. There were no significant differences in intestinal metaplasia between PPI and non-PPI users.

\section{The duration of PPI use correlated with inhibition of neutrophil and $H$. pylori infiltration}

Figure 1 shows the duration of PPI use among patients with different grades of gastric neutrophil infiltration (22 patients with no neutrophil infiltration, 26 with mild infiltration, 16 with moderate and 12 with marked infiltration; $79.32 \pm 117.67,26.12 \pm 81.04,8.38 \pm 29.97$, and $0.00 \pm 0.00$, respectively; $p=0.004)$. Patients with decreased neutrophil infiltration tended to have taken PPIs

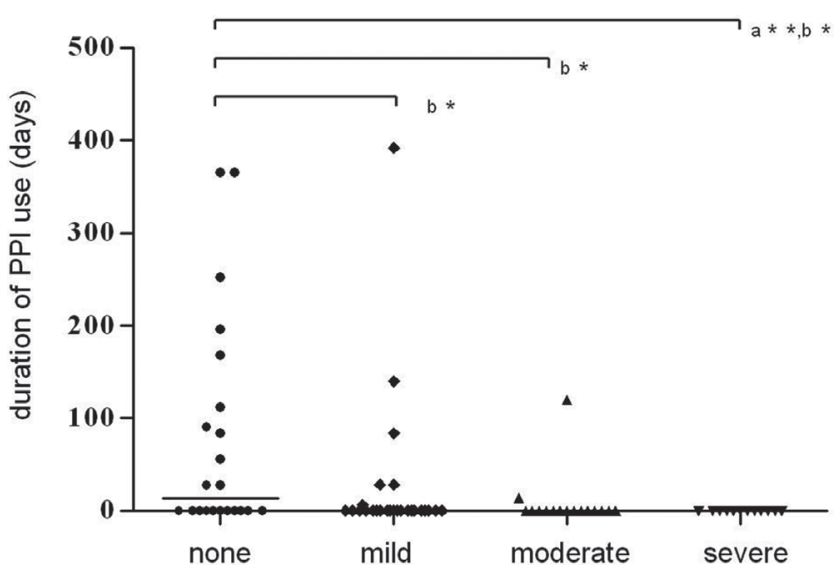

Fig. 1. The duration of PPI use among patients with different grades of neutrophil infiltration in the gastric mucosa. The Kruskal-Wallis test was used for comparison of four groups and the Mann-Whitney $U$ test was used for comparison between each group and none group; a) Kruskal-Wallis test; b) Mann-Whitney $U$ test; ${ }^{*} p<0.05$ )

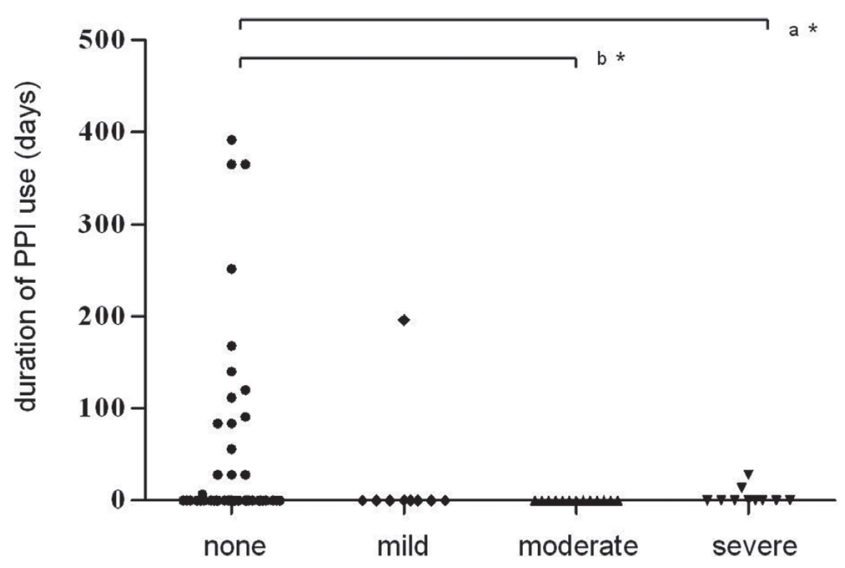

Fig. 2. The duration of PPI use among patients with different grades of H. pylori infiltration in the gastric mucosa. The Kruskal-Wallis test was used for comparison of four groups and Mann-Whitney $U$ test was used for comparison between each group and none group; a) Kruskal-Wallis test; b) Mann-Whitney $U$ test; * $p<0.05$ )

for longer durations prior to endoscopic examination. The duration of PPI use also had a significant effect on H. pylori infiltration (Fig. 2).

\section{PPI use was associated with decreased neutrophil infiltration and increased mucosal atrophy}

Tables 3 a and $3 \mathrm{~b}$ present the results of forward stepwise logistical regression analysis of PPI use. PPI use was associated with decreased neutrophil infiltration and increased mucosal atrophy.

Table 3 a. Stepwise logistic regression analysis of the effect of PPI use (total number of patients: $n=76$ )

\begin{tabular}{|c|c|c|c|c|c|c|c|}
\hline $\begin{array}{l}\text { Variable } \\
\text { (cutoff) }\end{array}$ & $\begin{array}{l}\text { Regression } \\
\text { coefficient }\end{array}$ & S.E. & Odds ratio & \multicolumn{3}{|c|}{$95 \% \mathrm{Cl}$ of odds ratio } & P-value \\
\hline \multicolumn{7}{|l|}{ Neutrophil activity } & $0.007^{* *}$ \\
\hline Neutrophil activity (mild) & -1.204 & 0.631 & 0.30 & 0.09 & - & 1.03 & 0.056 \\
\hline Neutrophil activity (moderate, severe) & -2.565 & 0.849 & 0.08 & 0.01 & - & 0.41 & $0.003 * *$ \\
\hline Constant & 0.000 & 0.426 & 1.00 & & & & 1.000 \\
\hline
\end{tabular}

${ }^{*} p<0.05$ (tested by Wald statistics); accuracy of model = 75.0\%; regression mode: forward stepwise.

Table $3 \mathrm{~b}$. Stepwise logistic regression analysis of the effect of PPI use (in relation to the number of patients with gastric mucosa atrophy evaluation; $\mathrm{n}=46$ )

\begin{tabular}{|c|c|c|c|c|c|c|c|}
\hline $\begin{array}{l}\text { Variable } \\
\text { (cutoff) }\end{array}$ & $\begin{array}{l}\text { Regression } \\
\text { coefficient }\end{array}$ & S.E. & Odds ratio & \multicolumn{3}{|c|}{$95 \% \mathrm{Cl}$ of odds ratio } & P-value \\
\hline \multicolumn{7}{|l|}{ Neutrophil activity } & 0.084 \\
\hline Neutrophil activity (mild) & -3.292 & 1.528 & 0.04 & 0.00 & - & 0.74 & $0.031 *$ \\
\hline Neutrophil activity (moderate/severe) & -2.062 & 1.265 & 0.13 & 0.01 & - & 1.52 & 0.103 \\
\hline Atrophy & 3.317 & 1.364 & 27.57 & 1.90 & - & 399.40 & 0.015 * \\
\hline Constant & -0.630 & 0.685 & 0.53 & & & & 0.357 \\
\hline
\end{tabular}

${ }^{*} \mathrm{p}<0.05$ (tested by Wald statistics); accuracy of model = 80.5\%; regression model: forward stepwise. 


\section{Discussion}

The study showed that PPIs affect the microenvironment of the gastric mucosa. PPI users in the study group had less neutrophil and lymphocyte infiltration in the gastric mucosa than non-users. In addition, PPI use also affected $H$. pylori infiltration in the gastric mucosa and induced gland atrophy.

PPIs may affect leukocyte infiltration and the gastric mucosal gland. Furthermore, PPIs may be related to the course of gastric inflammation and carcinogenesis. A previous study suggested that PPIs may attenuate neutrophil-related oxidative stress and phagocytosis. $3,9,10,12$ PPI-induced agranulocytosis and impaired lymphocyte functions have recently been reported. ${ }^{11,17}$ The neutrophils that infiltrate gastric mucosa are affected by PPIs. PPIs can attenuate neutrophil adherence to endothelial cells by inhibiting the expression of adhesion molecules. ${ }^{13}$ The results of the current study indicated that PPIs may attenuate the infiltration of neutrophils in the gastric antral mucosa. Infiltrating neutrophils play an important role in gastric mucosal injury, particularly in regard to oxidative stress and inflammatory cytokines. ${ }^{6}$ Gastric mucosa neutrophils also defend against foreign bacterial infection. The effect of PPIs on gastric mucosa neutrophil-related oxidative stress and the innate immunity of neutrophils in the gastric mucosa need further investigation, particularly considering the heterogeneity of human hosts.

Gastric mucosa glandular distribution and inflammatory cytokine production are also affected by PPIs. Two components of gastric inflammatory status, intestinal metaplasia and glandular atrophy, have been studied. A previous report suggested PPI use may be related to mucosal atrophy, but not intestinal metaplasia. There also may be complex biological interactions among PPIs, $H$. pylori, gastritis and carcinogenesis, but the mechanisms of such interactions have not been clarified. In the natural course of $H$. pylori infection, the location of $H$. pylori, acid secretion, PPI use and neutrophil infiltration are all important components in the development of gastritis.

The effect of PPIs on gastric neoplasms has not yet been decisively clarified. PPI use may be related to atrophy of the gastric glands, which in turn may be linked to carcinogenesis. However, a relationship between PPI use and cancer has not been established. The results of animal studies on the role of PPIs in inflammation and carcinogenesis are controversial. Yeo et al. demonstrated that PPIs suppressed $H$. pylori-induced angiogenesis. ${ }^{18}$ Hagiwara et al. reported that long-term PPI use exacerbated atrophic gastritis and promoted carcinogenesis. ${ }^{19}$ In the present study, PPI use was related to glandular atrophy. PPIs may play a role in the course of gastritis, atrophic gastritis, intestinal metaplasia and carcinogenesis.

One limitation of this study was the small number of subjects enrolled; another was the fact that the quantity of neutrophils was not measured over the corpus of stomach. In addition, chemokine activity (for example, interleukin-8) was not evaluated in relation to neutrophil infiltration; clarification of the mechanism of neutrophil attraction will require further study.

\section{Conclusions}

The study showed that PPIs modified the microenvironment of gastric mucosa. PPIs use attenuated the infiltration of neutrophils and $H$. pylori in the gastric mucosa. The suppressive effect of PPIs on neutrophil and $H$. pylori infiltration was also related to the duration of PPI use.

\section{References}

1. Yang YX, Metz DC. Safety of Proton Pump Inhibitor Exposure. Gastroenterology. 2010;139:1115-1127.

2. Suzuki M, Suzuki H, Kitahora T, et al. Proton pump inhibitor modifies inflammatory reaction in human gastric mucosa infected by Helicobacter pylori. Aliment Pharmacol Ther. 2002;16(Suppl 2): 229-234.

3. Zedtwitz-Liebenstein K, Wenisch C, Patruta S, Parschalk B, Daxbock $\mathrm{F}$, Graninger W. Omeprazole treatment diminishes intra- and extracellular neutrophil reactive oxygen production and bactericidal activity. Crit Care Med. 2002;30:1118-1122.

4. Handa O, Yoshida N, Fujita N, et al. Molecular mechanisms involved in anti-inflammatory effects of proton pump inhibitors. Inflammation Research. 2006;55:476-480.

5. Sadik CD, Kim ND, Luster AD. Neutrophils cascading their way to inflammation. Trends Immunol. 2011;32:452-460.

6. Kozol R, Kopatsis A, Fligiel SE, Czanko R, Callewaert D. Neutrophil-mediated injury to gastric mucosal surface cells. Dig Dis Sci. 1994;39:138-144.

7. Suerbaum S, Michetti P. Helicobacter pylori infection. N Engl J Med. 2002;347:1175-1186.

8. Yoshikawa T, Naito Y. The role of neutrophils and inflammation in gastric mucosal injury. Free Radic Res. 2000;33:785-794.

9. Agastya G, West BC, Callahan JM. Omeprazole inhibits phagocytosis and acidification of phagolysosomes of normal human neutrophils in vitro. Immunopharmacol Immunotoxicol. 2000;22:357-372.

10. Suzuki M, Mori M, Miura S, et al. Omeprazole attenuates oxygenderived free radical production from human neutrophils. Free Radic Biol Med. 1996;21:727-731.

11. Scaringi L, Cornacchione $\mathrm{P}$, Fettucciari $\mathrm{K}$, et al. Activity inhibition of cytolytic lymphocytes by omeprazole. Scand J Immunol. 1996;44:204-214.

12. Wandall JH. Effects of omeprazole on neutrophil chemotaxis, super oxide production, degranulation, and translocation of cytochrome b-245. Gut. 1992;33:617-621.

13. Yoshida N, Yoshikawa T, Tanaka Y, et al. A new mechanism for anti-inflammatory actions of proton pump inhibitors - inhibitory effects on neutrophil-endothelial cell interactions. Aliment Pharmacol Ther. 2000;14 Suppl 1:74-81.

14. Kuipers EJ. Proton pump inhibitors and gastric neoplasia. Gut. 2006;55:1217-1221.

15. Suzuki M, Suzuki H, Hibi T. Proton pump inhibitors and gastritis. J Clin Biochem Nutr. 2008;42:71-75.

16. Sipponen P, Price AB. The Sydney System for classification of gastritis 20 years ago. J Gastroenterol Hepatol. 2011;26(Suppl 1):31-34.

17. Dury S, Nardi J, Gozalo C, Lebargy F, Deslee G. Agranulocytosis Induced by Proton Pump Inhibitors. J Clin Gastroenterol. 2012; 46:859.

18. Yeo M. Novel action of gastric proton pump inhibitor on suppression of Helicobacter pylori induced angiogenesis. Gut. 2006;55:26-33.

19. Hagiwara T, Mukaisho K, Nakayama T, Sugihara H, Hattori T. Longterm proton pump inhibitor administration worsens atrophic corpus gastritis and promotes adenocarcinoma development in Mongolian gerbils infected with Helicobacter pylori. Gut. 2011;60:624-630. 